Meatendra or both) increased digestibility considerably (by from 16 to $37 \%$ ), but that two had no significant effect.

3. It is suggested that the effectiveness of some of these methods in influencing digestibility is due to their ability to increase the surface area of the meat.

The author wishes to acknowledge much valuable guidance and assistance given by Professor R. V. Bradlaw, Dr G. N. Jenkins and Mr D. J. Newell. Thanks are also due to Dr J. H. Bushill of J. Lyons and Company Ltd, Mrs M. V. Jackson of the Northern Counties Training College of Cookery and Domestic Science and Mrs I. Alderson of the Good Housekeeping Institute for their advice on various aspects of the inquiry; to the subjects for their uncomplaining co-operation; and to Willing's Press Service Limited for a gift of Meatendra.

REFERENCE

Farrell, J. H. (1956). Brit. dent. F. roo, I49.

\title{
The rate of passage of foodstuffs through the alimentary tract of the goat
}

\section{Studies on growing kids}

By ELIZABETH J. CASTLE

Department of Veterinary Preventive Medicine, University of Liverpool

(Received 21 October 1955)

It has been shown that the passage of a stained marker through the alimentary tract follows a fairly constant pattern in adult sheep (Lenkeit, r930, I932), cattle (Balch, I950) and goats (Castle, 1956).

The relative sizes of the four compartments of the ruminant stomach alter from birth until the age of about 4 months, after which time the proportions remain almost constant. For example, at birth the abomasum is the largest compartment and is more than twice the size of the rumen, whereas in the adult the rumen is about ten times as large as the abomasum (Sisson, I953). The length of the intestine also increases as the animal grows. It would not therefore be surprising if these changes were reflected in alterations in the pattern of excretion of the food. It is well known that in the suckling ruminant milk passes directly into the abomasum by means of the oesophageal groove and only small amounts enter the rumen. The course of solid foods in young ruminants has not been extensively investigated.

Lenkeit \& Columbus (1934) found that chopped rye straw given in milk, water or oatmeal gruel, either as a drench or by stomach tube, was excreted more rapidly in lambs than in adult sheep. Since the straw was given in a fluid, however, its course 
might well be different from that of straw eaten in the normal way. Columbus (1936) found that the rate of passage of chopped straw given with food was slightly more rapid in a kid 7 months old than in an adult goat. Biondo (1953) measured the time of first and last appearance of stained oats in five kids $2-7$ months old and in five adult goats; he found that the younger the animal the earlier the time of first and last appearance of the marker. These differences occurred both between different animals and in the same animal as it grew up.

These findings suggest that solid food passes through the alimentary tract of young ruminants slightly more rapidly than in adults, but most of the experiments were carried out on weaned animals.

\section{EXPERIMENTAL}

\section{Plan of experiment}

A series of experiments with stained markers was carried out to measure the rate of passage of solid food in four kids, both before and after weaning. 'The observations were first made when the kids were 4 weeks old and were repeated at intervals of 3 weeks until they were 4 months old, by which time the values were almost constant. Three further experiments were carried out when the kids were 9, I2 and 15 months old, when they were eating the same rations as adults.

\section{Experimental animals and their management}

Four kids born on the same day were used. Kid no. I, a single, was from a Saanentype female mated with an Alpine male; kids nos. 2, 3 and 4 were triplets from a Nubian female by the same sire. The Saanen fostered kid no. 2 and the Nubian reared kids nos. 3 and 4 . Two of the kids (nos. I and 3 ) were females and two (nos. 2 and 4 ) were males; the latter were not castrated.

The kids were kept during the first 3 months of life in small wire-netting pens, about $3 \mathrm{ft}$. square, placed within sight of the dam. These pens had a false floor of expanded metal through which the faeces passed for collection. The young kids were removed from these pens four times a day and allowed to suck their mothers at approximately 4 -hourly intervals commencing at 8.30 a.m.

Hay and water were allowed $a d l i b$. at all ages, but in the experiments conducted after weaning the weight of hay eaten was measured, as at this stage the kids were large enough to be confined in crates designed for collection of faeces and measurement of food intake. The water consumption was also measured in the last three experiments, i.e. at 9,12 and $x_{5}$ months of age. Calf nuts were fed throughout at the rate of $40 \mathrm{~g}$ daily at the age of 4 weeks, increasing by 20 g every 3 weeks until the adult ration of $400 \mathrm{~g}$ daily was reached at 15 months. Kids of all ages were fed hay and nuts at 9.0 a.m. and 4.0 p.m. and were weighed weekly.

\section{Technique for measuring rate of passage}

The rate of passage of stained hay was measured in the same way as for adult goats (Castle, 1956).

During the first three experiments before weaning at 3 months, the rate of excretion 
of small stained faecal fragments as well as that of stained long hay was measured. The fragments were obtained by macerating normal goat faeces in hot water and passing them through a graded series of standard sieves. Fragments which passed through a sieve of mesh size $\mathrm{I} \cdot 0 \mathrm{~mm}$ but were retained by one of mesh size $0.297 \mathrm{~mm}$ were collected. These fragments, measuring about $0.3^{-1} \cdot 0 \mathrm{~mm}$, were well washed and stained in the same way as the hay, except that brilliant green was used instead of basic fuchsin. The stained faecal fragments were mixed with a small amount of powdered calf nuts and fed, together with hay stained red, between 9.20 and 9.40 p.m. on the Ist day of experiment. It was thus possible to follow the course of the two markers at the same time.

Because of the small amounts of faeces passed by the very young animals the interval between collections on the ist day could not be less than $4 \mathrm{~h}$. On the 2nd and 3 rd days it was $6 \mathrm{~h}$, and from then onwards faeces were collected twice daily.

\section{Interpretation of results}

Cumulative excretion curves were plotted for both the stained hay and the stained faecal fragments. The results were then expressed as the mean retention time $(R)$ in $\mathrm{h}$ (see Castle, 1956). To obtain $R$ the times of excretion of marker at intervals of $10 \%$ between 5 and $95 \%$ were added together and divided by ro, thus giving a mean value for time of excretion of marker.

\section{RESULTS}

\section{Stained hay}

At all ages, particles of stained hay were first detected in the faeces passed between the I I th and $15^{\text {th }} \mathrm{h}$ after feeding. In the sucking kids this time could not be determined with any more accuracy because of the $4 \mathrm{~h}$ interval between collections.

In the young sucking kids, the excretion of stained hay was not complete until the 7 th or 8 th day, whereas by the time the animals were weaned when 3 months old it ended $\mathbf{I}-2$ days earlier.

Excretion curves show the same general sigmoid shape throughout, but the mean retention time $(R)$ varied between $39^{\circ} 0$ and $71^{\circ} 5 \mathrm{~h}$. It can be seen from Table I that with three of the four kids the $R$ value was highest when they were 4 weeks old, and from then until the third measurement, just before weaning, it tended to fall progressively. After weaning, no major change in the $R$ value occurred. Fig. I shows the $R$ values for the four kids at the different ages, and illustrates the great decrease that occurred between I and 3 months. This fall was most marked in kids nos. 3 and 4 , less detectable in kid no. I and hardly detectable in kid no. 2.

Fig. I also shows other slight differences between individuals. Kid no. 2, for example, almost invariably had a lower $R$ value than the other three, and kid no. 4 generally had the highest one. There was no striking difference between the two sexes.

The times for $5 \%$ excretion of marker also varied considerably with age (Table $\mathrm{I}$ ), the highest value $(35 \mathrm{~h})$ being obtained with kid no. 4 when I month old. This was more than twice the lowest value, $\mathrm{I} 4 \mathrm{~h}$, obtained for the same goat when 9 months old. The continuous fall in the $5 \%$ excretion time which occurred up to the age of 4 months 
Table I. Body-weight; times of mean retention $(R)^{*}, 5$ and $95 \%$ excretion; dry-matter content of faeces, measured in eight experiments on each of four kids at various ages from I to I 5 months

Time (h) of

* See p. 117 .

\begin{tabular}{|c|c|c|c|c|c|c|c|c|}
\hline \multirow[b]{2}{*}{ Kid no. } & \multirow[b]{2}{*}{ Sex } & \multirow[b]{2}{*}{ Age } & \multirow{2}{*}{$\begin{array}{c}\text { Body- } \\
\text { weight } \\
(\mathrm{kg})\end{array}$} & \multirow{2}{*}{$\begin{array}{l}\text { Mean } \\
\text { retention } \\
(R)\end{array}$} & \multirow[b]{2}{*}{$\begin{array}{c}5 \% \\
\text { excretion }\end{array}$} & \multirow[b]{2}{*}{$\begin{array}{c}95 \% \\
\text { excretion }\end{array}$} & \multicolumn{2}{|c|}{$\begin{array}{c}\text { Dry-matter conter } \\
\text { of faeces }\end{array}$} \\
\hline & & & & & & & g/day & $\%$ \\
\hline \multirow[t]{7}{*}{ I } & 우 & $\begin{array}{l}4 \text { weeks } \\
7\end{array}$ & $\begin{array}{l}6 \cdot 7 \\
8 \cdot 7\end{array}$ & $\begin{array}{l}52 \cdot 4 \\
42 \cdot 9\end{array}$ & $\begin{array}{l}24.0 \\
18.0\end{array}$ & $\begin{array}{l}88 \cdot 5 \\
78 \cdot 0\end{array}$ & $\begin{array}{l}26 \cdot I \\
84 \cdot 5\end{array}$ & $\begin{array}{l}52 \cdot 5 \\
49 \cdot 5\end{array}$ \\
\hline & & 10 & $1 \mathrm{I} \cdot \mathrm{I}$ & $43 \cdot 4$ & $21 \cdot 5$ & $75^{\circ} \circ$ & $86 \cdot 0$ & $53 \cdot 8$ \\
\hline & & 13 & $12 \cdot 7$ & $44^{\circ} 4$ & $20 \%$ & $78 \cdot 0$ & $120^{\circ} 0$ & $53 \cdot 8$ \\
\hline & & 16 & 13.9 & $4 I \cdot 8$ & $18 \cdot 0$ & $75^{\circ} \circ$ & $197^{\circ} 0$ & $47 \cdot 4$ \\
\hline & & 9 months & 18.7 & 443 & $18 \cdot 0$ & 84.0 & $229^{\circ} 0$ & $50 \cdot 1$ \\
\hline & & 12 & $2 x \cdot 2$ & $46 \cdot 9$ & 17.0 & $88 \cdot 0$ & $235^{\circ} 0$ & 50.4 \\
\hline & & $I_{5}$ & $28 \cdot 2$ & $46 \cdot 1$ & $18 \cdot 0$ & $85^{\circ} 0$ & $315^{\circ} \circ$ & $49 \cdot 2$ \\
\hline \multirow[t]{8}{*}{2} & 0 & 4 weeks & $8 \cdot 5$ & $42 \cdot 6$ & 19.0 & $7 I \cdot 0$ & 38.0 & $52 \cdot 3$ \\
\hline & & 7 & I I $\cdot 3$ & $44^{\circ} I$ & $20 \cdot 0$ & $78 \cdot 0$ & 100.0 & $50 \cdot 3$ \\
\hline & & 10 & 14.5 & $39^{\circ} \circ$ & 19.0 & $72 \cdot 0$ & I I $4 \cdot 0$ & $52 \cdot 3$ \\
\hline & & 13 & $16 \cdot 2$ & $44^{\circ} 7$ & 24.0 & $65 \cdot 0$ & $175^{\circ} 0$ & $51 \cdot 3$ \\
\hline & & 16 & $17 \cdot 4$ & 39.4 & 18.0 & $69 \cdot 0$ & $264^{\circ} 0$ & $50 \cdot 2$ \\
\hline & & 9 months & $26 \cdot 9$ & $39^{\circ} \circ$ & 15.5 & $75 \circ$ & $442 \cdot 0$ & 40.6 \\
\hline & & 12 & $3 I \cdot 5$ & 40.5 & 16.5 & $77 \cdot 0$ & $397^{\circ} \circ$ & $3^{8 \cdot 2}$ \\
\hline & & I 5 & $4 I \cdot 2$ & $40 \cdot 9$ & $15{ }^{\circ} 0$ & $77 \cdot 0$ & $53^{8 \cdot 0}$ & $33 \cdot 3$ \\
\hline \multirow[t]{8}{*}{3} & 우 & 4 weeks & $8 \cdot 3$ & $6 r \cdot 0$ & $26 \cdot 0$ & 102.0 & $40 \cdot 0$ & $56 \cdot 3$ \\
\hline & & 7 & II 2 & $43^{\circ} 0$ & $19^{\circ} 0$ & 84.0 & 96.0 & $46 \cdot 8$ \\
\hline & & 10 & $13 \cdot 1$ & $41 \cdot 0$ & 16.0 & $87 \cdot 0$ & $122 \cdot 0$ & $49^{\circ} 0$ \\
\hline & & I3 & $15 \cdot 2$ & 44.5 & $18 \cdot 0$ & 84.0 & I 80.0 & $44^{\circ} 0$ \\
\hline & & 16 & 16.4 & $43^{\circ} 9$ & $16 \cdot 0$ & $96 \cdot 0$ & $228 \cdot 0$ & $39^{\circ} 4$ \\
\hline & & 9 months & 23.5 & $45^{\cdot 2}$ & 15.0 & $87 \cdot 0$ & $388 \cdot 0$ & $42 \cdot 0$ \\
\hline & & I 2 & $22 \cdot 7$ & $4 I \cdot 5$ & $15 \cdot 0$ & 84.0 & $25 \times 0$ & $48 \cdot 0$ \\
\hline & & I5 & $30 \cdot 3$ & $46 \cdot 7$ & $17 \cdot 0$ & $87 \cdot 0$ & $420 \cdot 0$ & $38 \cdot 8$ \\
\hline \multirow[t]{8}{*}{4} & $\hat{o}$ & 4 weeks & $9 \cdot 3$ & $71 \cdot 3$ & $35^{\circ} \circ$ & $I^{1} 4.0$ & $35 \cdot 5$ & $56 \cdot 6$ \\
\hline & & 7 & $12 \cdot 0$ & $49 \cdot 7$ & $25^{\circ} 0$ & 90.0 & $80 \cdot 0$ & $42 \cdot 8$ \\
\hline & & 10 & $15 \cdot 2$ & $42 \cdot 7$ & $20 \cdot 0$ & $78 \cdot 0$ & $126 \cdot 0$ & 55.3 \\
\hline & & 13 & $17 \cdot 3$ & $42 \cdot 9$ & $18 \cdot 0$ & 84.0 & I 80.0 & $49 \cdot 8$ \\
\hline & & 16 & $18 \cdot I$ & $44 \cdot 5$ & $17 \cdot 0$ & 87.0 & $226 \cdot 0$ & $44^{\cdot I}$ \\
\hline & & 9 months & $25 \cdot I$ & $45^{\circ} 4$ & 14.0 & 86.0 & $35^{8 \cdot 0}$ & $43 \cdot 4$ \\
\hline & & 12 & 29.6 & $43^{\circ} \cdot$ & $18 \cdot 0$ & 84.0 & $347^{\circ} \circ$ & $44 \cdot 6$ \\
\hline & & I 5 & $38 \cdot 0$ & $42 \cdot I$ & 14.0 & 84.0 & $447^{\circ} \circ$ & $39: 3$ \\
\hline
\end{tabular}

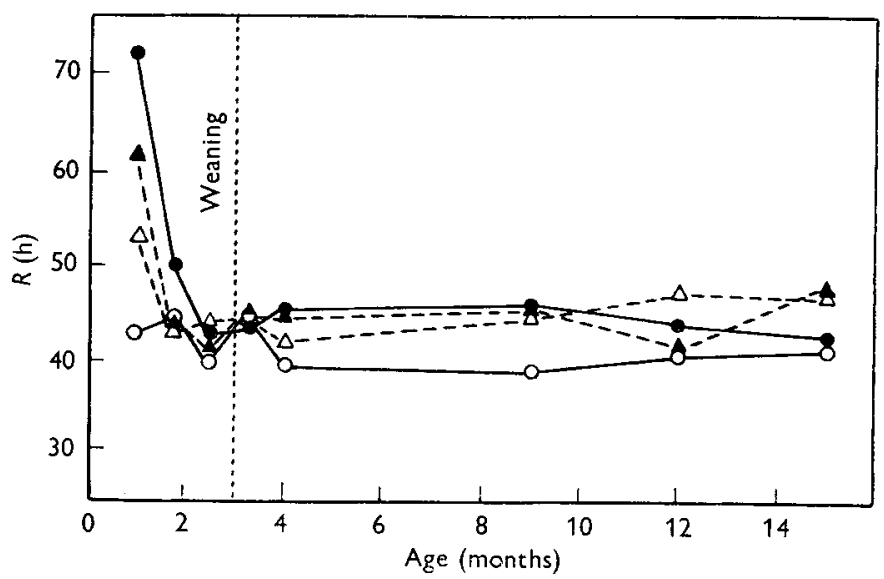

Fig. I. Individual values for mean retention time $(R)$ (see p. II $)$ of stained hay for each of four kids

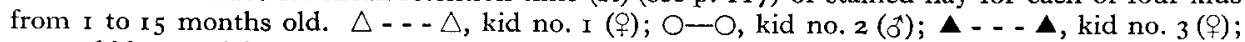
$\longrightarrow$, kid no. $4(\hat{o})$. 
is shown in Fig. 2c. A similar fall occurred in the time of $95 \%$ excretion between I and 3 months (Fig. 2a). Unlike the $5 \%$ excretion time, however, the $95 \%$ excretion time rose again after weaning and increased slightly with age for the next few months. The mean retention times $(R)$ for the four kids are also shown in Fig. $2 b$ for comparison with the 5 and $95 \%$ excretion times.

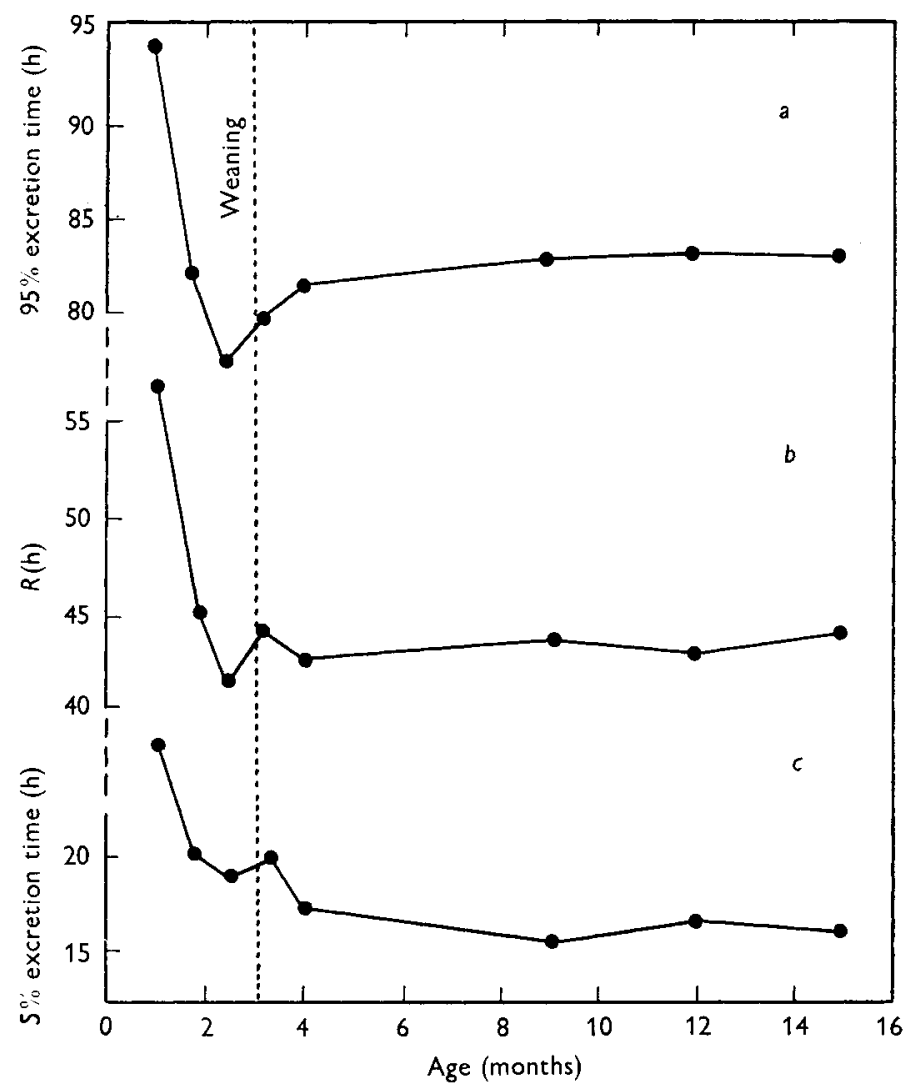

Fig. 2. Mean values for $(a) 95 \%$ excretion time, $(b)$ mean retention time $(R)$ (see p. 117 ) and (c) $5 \%$ excretion time of stained hay for four kids from $\mathrm{I}$ to 15 months old.

These results indicate that in unweaned kids a month old the rate of passage of hay as measured by the mean retention time $(R)$ is much slower than when they are adult (Fig. $2 b$ ). The increase in rate of passage is almost complete by weaning time and is brought about by an increase in the rate of all stages of excretion (Fig. $2 a$ and $c$ ).

\section{Stained faecal fragments}

In each experiment in which the two markers (green faecal fragments and red hay) were used, their first appearance in the faeces occurred at the same time, namely, in the sample collected between the IIth and ${ }^{5} 5^{\text {th }} \mathrm{h}$ after feeding. From that time onward, however, the green particles were excreted more rapidly than the red particles derived from the stained hay, and hence the net excretion curves obtained with the former tended to be nearer the vertical (Fig. 3). The $R$ values for the faecal fragments 
were less than those for the hay, the maximum difference between the two being I9. $5 \mathrm{~h}$ and the minimum difference $12.8 \mathrm{~h}$ (Table 2 and Fig. 4). From Table 2 it will be seen that the difference between the two $R$ values was always greater in kids nos. 3 and 4 than in kids nos. 1 and 2 , and that this difference was greater between kids than between the different results for one kid. For each individual kid the difference in time between the two markers changed very little with age, the largest difference being that of $3 \mathrm{~h}$ between the experiments on kid no. 3. The difference did not exceed $\mathrm{I} \cdot \mathrm{I}$ and $0.8 \mathrm{~h}$ with kids nos. I and 2 respectively.

These results show that when a finely divided marker consisting of stained faecal residues is fed by mouth to young kids, the rate of passage is considerably faster than that of long, stained hay, and the difference is certainly due to a difference in the rate of passage through the reticulo-ruminal sack, for the first appearance of both markers in the same sample of faeces indicates that both passed at the same rate from the omasum caudally.

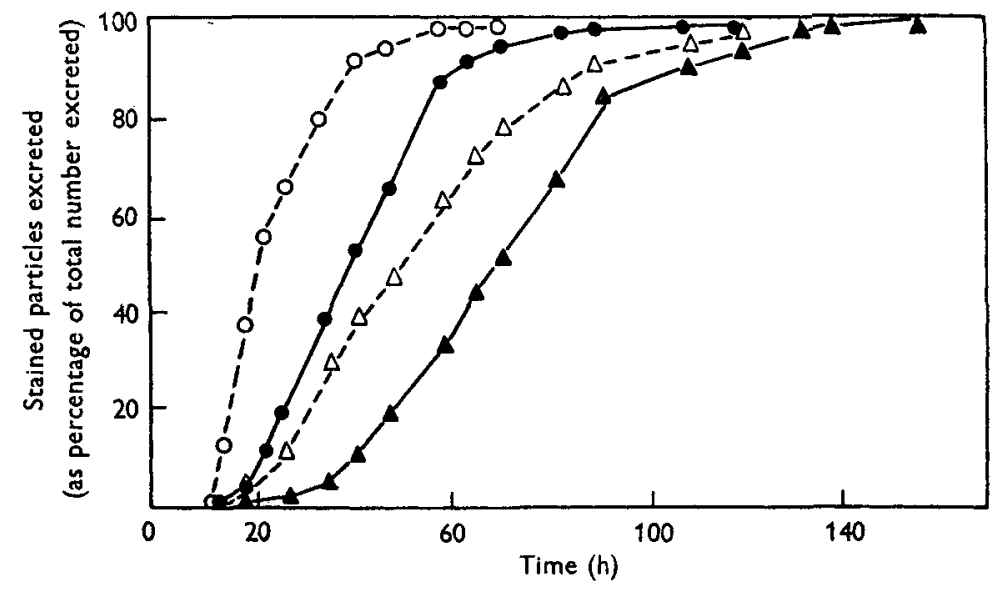

Fig. 3. Rates of excretion of undigested stained hay residues and of stained faecal fragments by kid no. 4 when 4 and ro weeks old. $\Delta--\triangle \Delta, 4$ weeks old, faecal fragments; $\Delta-\Delta, 4$ weeks old, hay residues; $\mathrm{O}_{-}-\mathrm{O}$, 10 weeks old, faecal fragments; - , 10 weeks old, hay residues.

Table 2. Mean retention times $(R) *$ obtained with two markers, stained hay and stained faecal fragments, for four kids at ages 4,7 and 1o weeks

\begin{tabular}{|c|c|c|c|c|c|}
\hline \multirow[b]{2}{*}{ Kid no. } & \multirow[b]{2}{*}{ Sex } & \multirow[b]{2}{*}{ Age (weeks) } & \multicolumn{2}{|c|}{ Mean retention time $(R)(\mathrm{h})$} & \multirow{2}{*}{$\begin{array}{l}\text { Difference } \\
\text { between the two } \\
R \text { values }(\mathrm{h})\end{array}$} \\
\hline & & & Hay & Faecal fragments & \\
\hline $\mathbf{I}$ & $q$ & $\begin{array}{r}4 \\
7 \\
10\end{array}$ & $\begin{array}{l}52 \cdot 4 \\
42 \cdot 9 \\
43 \cdot 4\end{array}$ & $\begin{array}{l}39 \cdot 0 \\
29 \cdot 0 \\
31 \cdot 6\end{array}$ & $\begin{array}{l}13 \cdot 4 \\
13 \cdot 9 \\
12 \cdot 8\end{array}$ \\
\hline 2 & $\sigma$ & $\begin{array}{r}4 \\
7 \\
10\end{array}$ & $\begin{array}{l}42 \cdot 6 \\
44^{\cdot I} \\
39 \cdot 0\end{array}$ & $\begin{array}{l}29^{\circ} 0 \\
29^{\circ} 4 \\
25^{\circ} 1\end{array}$ & $\begin{array}{l}\text { r } 3 \cdot 6 \\
14 \cdot 7 \\
\text { r } 3 \cdot 9\end{array}$ \\
\hline 3 & q & $\begin{array}{r}4 \\
7 \\
10\end{array}$ & $\begin{array}{l}6 I \cdot 0 \\
43 \cdot 0 \\
41 \cdot 0\end{array}$ & $\begin{array}{l}4 x \cdot 5 \\
26 \cdot 5 \\
23 \cdot 9\end{array}$ & $\begin{array}{l}19 \cdot 5 \\
16 \cdot 5 \\
17 \cdot 1\end{array}$ \\
\hline 4 & $\sigma$ & $\begin{array}{r}4 \\
7 \\
10\end{array}$ & $\begin{array}{l}71 \cdot 3 \\
49 \cdot 7 \\
42 \cdot 7\end{array}$ & $\begin{array}{l}5 I \cdot I \\
32 \cdot 9 \\
24 \cdot 9\end{array}$ & $\begin{array}{l}17 \cdot 2 \\
16 \cdot 8 \\
17 \cdot 8\end{array}$ \\
\hline
\end{tabular}




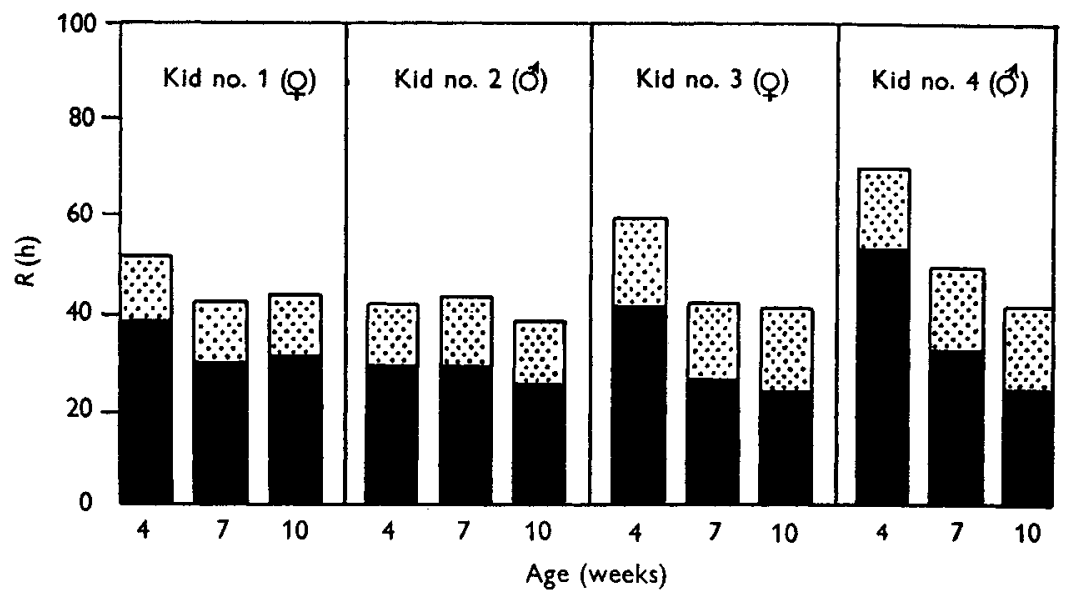

Fig. 4. Mean retention times $(R)$ (see p. II7) for stained hay and stained faceal fragments for individual kids when 4,7 and ro weeks old. $\square$, faecal fragments; 圈, difference between faecal fragments and stained hay.

\section{Factors which may be related to rate of passage}

In general, the total food intake from 3 to 15 months increased progressively with age, this increase being most marked in the early stages of growth. Kids nos. 2, 3 and 4 at each age consumed about the same amount of dry matter (Table 3), whereas kid no. $I$ ate less hay than the others, but always consumed its ration of nuts; even so there was no outstanding difference in $R$ value between this animal and kids nos. 2, 3 and 4 .

Table 3. Food intake by kids from 13 weeks to 15 months old and total water intake (see p. 123) by kids from 9 to 15 months old

\begin{tabular}{|c|c|c|c|c|}
\hline Kid no. & Sex & Age & $\begin{array}{l}\text { Food intake } \\
\text { (g dry } \\
\text { matter/day) }\end{array}$ & $\begin{array}{l}\text { Water intake } \\
\text { (1./day) }\end{array}$ \\
\hline \multirow[t]{5}{*}{$\mathbf{I}$} & 우 & I3 weeks & 298 & - \\
\hline & & 16 & 415 & - \\
\hline & & 9 months & 582 & 1.00 \\
\hline & & I2 & 600 & 0.87 \\
\hline & & $\mathrm{r}_{5}$ & 756 & $1 \cdot 40$ \\
\hline \multirow[t]{5}{*}{2} & $\delta$ & I 3 weeks & 346 & - \\
\hline & & 16 & 500 & - \\
\hline & & 9 months & 972 & $1 \cdot 48$ \\
\hline & & 12 & 874 & 1.82 \\
\hline & & 15 & 1020 & $2 \cdot 39$ \\
\hline \multirow[t]{5}{*}{3} & 웅 & I3 weeks & 405 & 一 \\
\hline & & & 484 & - \\
\hline & & 9 months & 906 & $1 \cdot 33$ \\
\hline & & 12 & 690 & $x \cdot 29$ \\
\hline & & I5 & 964 & $1 \cdot 48$ \\
\hline \multirow[t]{5}{*}{4} & 3 & I3 weeks & 396 & - \\
\hline & & 16 & 495 & - \\
\hline & & 9 months & 852 & $1 \cdot 09$ \\
\hline & & 12 & 825 & $I \cdot 40$ \\
\hline & & I5 & 1090 & $2 \cdot 18$ \\
\hline
\end{tabular}


In the unweaned kids measurement of total food intake was not possible, but the total weight of faecal dry matter passed daily varied very little between kids of the same age (Table I), which indicated a fairly level food intake. It was noticed, however, that kids nos. 3 and 4 spent much longer sucking than the other two, and that their dam gave a much better supply of milk.

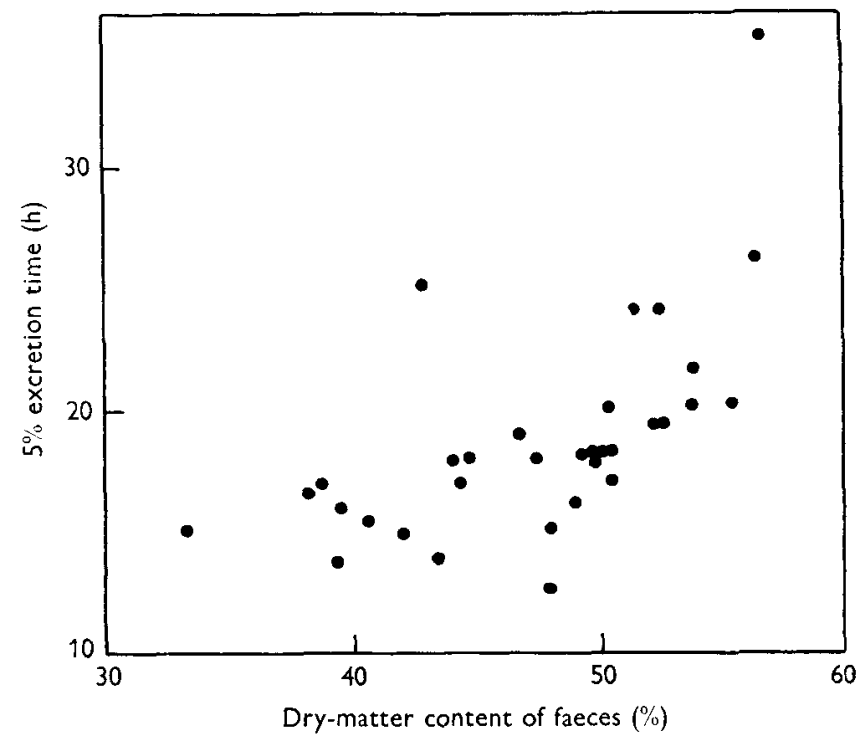

Fig. 5. Relationship between the $5 \%$ excretion time of coloured hay and the dry-matter content of the faeces. Values for four kids $1-15$ months old.

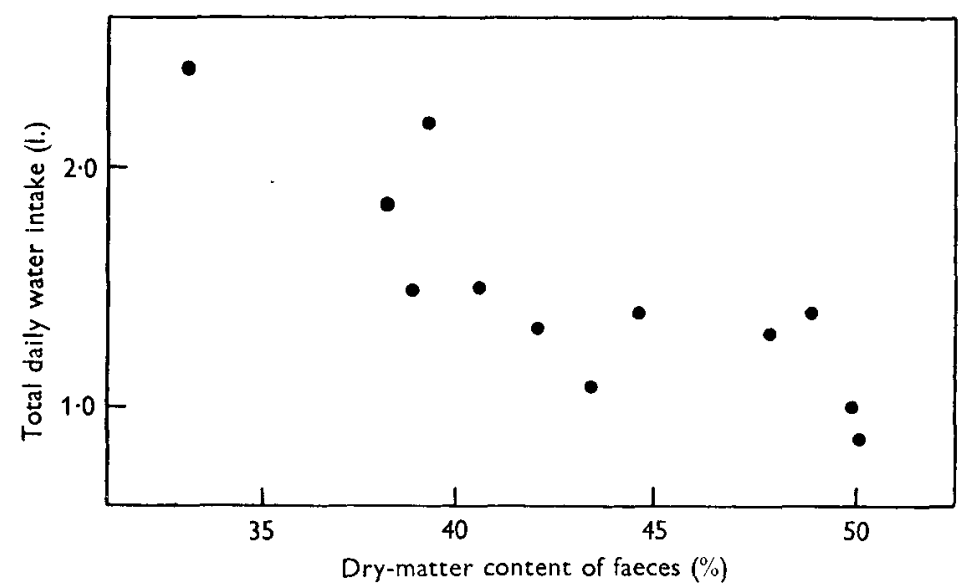

Fig. 6. Relationship between the dry-matter content of the faeces and the total daily water intake (see p. 123). Values for four kids in the last three experiments at 9 , I2 and 15 months old.

With only occasional exceptions the dry-matter content of the faeces decreased progressively with age (Table I). For example, the mean value for all the kids when I month old was $54.4 \%$, at 4 months $45.3 \%$ and at 15 months $4.0 \cdot 2 \%$.

As was found previously with adult goats (Castle, I956) a statistically significant relationship $(P<0.01)$ existed between the mean dry-matter content of the faeces during the experiment and the time of $5 \%$ excretion of marker (Fig. 5). 
It was observed in the experiments conducted on kids when ${ }_{3} 3$ and 16 weeks old that the kids that drank most water had the lowest faecal dry-matter content, so in the last three experiments (at 9,12 and 15 months) the total daily water intake, that is the sum of the voluntary water consumption and the calculated water intake in the food, was measured, and the results are given in Table 3. Again there seemed to be a relationship between water intake and content of water in the faeces. For example, when 15 months old kid no. I consumed an average of $I \cdot 41$. a day and the mean drymatter content of its faeces was $49 \cdot 2 \%$, whereas kid no. 2 at the same age consumed 2.41 . a day and had a faecal dry-matter content of only $33.3 \%$. A correlation coefficient calculated between daily water intake and faecal dry-matter content (Fig. 6) showed a statistically significant relationship between these two factors $(P<0.01)$.

\section{DISCUSSION}

The results of these experiments show that the rate of passage of a stained marker in young goats tends to increase between $\mathrm{I}$ month and weaning at 3 months, and then remains fairly constant.

The only other worker who has investigated this problem in a sufficient number of animals from which to draw any conclusions is Biondo (1953), who found that the first and last appearance of stained oats occurred earlier in young kids than in older kids or adults. Biondo, however, used kids 2 months of age and older, which were already weaned, and his results are thus not comparable with the present findings in sucking kids. Direct comparisons with his results on weaned kids also cannot be made, because the animals he used were given green fodder as well as hay and husks, and the addition of green food might well increase the total water intake above that of kids fed only on dry foods. Another difference which makes comparison with Biondo's work difficult is that he measured only the first and last appearance of the marker. The time of the last appearance is especially difficult to measure with any accuracy. In the present experiments the mean retention times $(R)$ when the kids were 15 months old ranged from $40 \cdot 9$ to $46 \cdot 7 \mathrm{~h}$, which is considerably higher than the range $32 \cdot 2-44.8 \mathrm{~h}$ obtained with the eight adult goats used in previous experiments and given the same foodstuffs (Castle, I956). This difference might be due to the considerable normal variation between individual adult goats, especially as the animals were of different breeding from those used previously.

There are various factors which may well contribute to the slowing down of the rate of passage in sucking kids: these include ( $\mathrm{r}$ ) the small quantity of solid food consumed, (2) the state of division of the rumen contents and (3) underdevelopment of co-ordinated ruminal movements.

(I) The unweaned kids only consumed small quantities of hay at irregular intervals, and although it was not possible to record the total weight of hay consumed at this age, figures for the total weight of faecal dry matter passed daily (Table r) give an indication of the quantity eaten. At 4 weeks of age, very little faeces was passed, but at 7 weeks the weight excreted per unit body-weight had almost doubled, indicating a considerable increase in solid-food intake, since there is very little dry-matter residue from milk. The time at which this marked change in faecal dry-matter excretion occurred 
coincided with the marked increase in the passage of the food through the tract as shown in Fig. I. Ingestion of solid food with a low digestibility might well increase the rate at which the small rumens of these animals emptied. Thus it has been shown with sheep that the amount of food given is a major determinant of passage (Blaxter, Graham \& Wainman, 1955) and preliminary trials with goats confirm this finding.

(2) It is generally recognized that foodstuffs such as hay do not leave the reticulorumen until they have reached a certain state of subdivision, this breaking-down process being accomplished by both rumination and the rumen flora. Very young ruminants do not spend long in rumination nor have they got such an efficient rumen flora as adults; hence hay would have to remain in the reticulo-rumen longer before it was broken down to sufficiently small particles.

(3) The third possible reason for the effect of age on food passage, namely, that in the infant animal rumen movements have less propulsive force and are incoordinated, received some support from the work of Phillipson (1939) with lambs, but as no direct measurements in these kids have been made, it appears more likely from earlier discussion that the major factor is indeed the change in the solid-food intake as the animal grows.

When the two markers, stained hay and stained faecal fragments, were fed concurrently, the small fragments invariably travelled much faster than the hay, this difference in rate of passage remaining almost constant at all ages. The increased rate of excretion of the small particles may well be due mainly to their size, for both Lenkeit (1930) and Balch (I950) have shown that oats and hay are excreted more rapidly when given ground than when given whole. The fact that the difference between the results obtained with the two markers remained almost constant at the different ages suggests that separation of the particles, presumably at the rumen omasal orifice, is unaffected by age. Such a conclusion involves also considerations of the rates of comminution of the long material in animals of different ages.

To determine accurately the length of time the marker spent in the different sections of the alimentary tract, it would be necessary to introduce markers into cannulas placed at different levels. Balch (1950) showed in cows that the $5 \%$ excretion time of stained hay represents the time taken for it to traverse omasum, abomasum and intestines. It is not known whether the same holds true for sucking animals, but if it does do so, then the rate of passage through the posterior regions of the alimentary tract is also slower in unweaned kids and increases up to 4 months of age.

In the experiments in which the water intake was measured at 9,12 and 15 months of age, a positive relationship was observed between total water intake and water content of the faeces. Whether low consumption of water was responsible for the low water content of the faeces in the very young kids could not be ascertained, as the amount of milk ingested was not measured. It is of interest, however, that when from 4 to 7 weeks old the kids did not drink any of the water offered to them.

In three of the four kids the increase in the water content of the faeces with age was pronounced; the young kids had very hard, dry faeces, but as they aged the faeces became softer. The dry-matter content was found to be linked with the $5 \%$ excretion time of the stained hay. 
A certain amount of individual variation was observed in the four kids. Kid no. 2 generally had a lower $R$ value than the others. No outstanding differences were observed between the two males and the two females.

Further studies on rate of passage in young unweaned ruminants are needed, with different markers at different ages. Hay is essentially the food of the weaned ruminant, which is better equipped to deal with cellulose than is the very young animal.

\section{SUMMARY}

x. Eight experiments to determine the rate of passage of foodstuffs were carried out on four kids between the ages of $I_{\text {Ind }}$ an months. The kids were allowed to suck until 3 months old, and received a weighed ration of calf nuts which increased with age up to 15 months. Hay was given ad lib. throughout, and the daily intake, which increased with age, was measured with kids over 3 months old. Under this age the intake was very small.

2. In all experiments hay stained red was given as a marker, the undigested coloured particles excreted were counted in samples of faeces, and the mean retention time $(R)$ of this marker was calculated.

3. In three experiments conducted before weaning, dried, sieved faeces from normal goats were stained green and were fed along with the hay stained red. Both stained markers first appeared in the faeces $\mathrm{I} I-15 \mathrm{~h}$ after feeding, which indicates an equal rate of passage through the omasum, abomasum and intestines. The remainder of the stained faecal fragments was excreted more rapidly than the stained hay, which suggests that the larger particles of hay were retained in the reticulo-rumen for a longer time.

4. The rate of passage of the stained hay increased up to weaning, and then remained fairly constant.

5. The dry-matter content of the faeces was highest in the very young kids, and tended to decrease up to 4 months of age.

6. The dry-matter content of the faeces showed a significant positive correlation with the $5 \%$ excretion time of stained hay and a significant negative correlation with the total water intake.

I would like to thank Professor E. G. White for his constant help and advice, and the Agricultural Research Council for a grant which enabled the work to be carried out. I would also like to thank Mrs J. Manly for her technical assistance, and Mr P. R. Witter for his care of the animals.

\section{REFERENCES}

Balch, C. C. (1950). Brit. F. Nutr. 4, 361.

Biondo, G. (1953). Nuova Vet. 29, 97.

Blaxter, K. L., Graham, N. McC. \& Wainman, F. W. (1955). Proc. Nutr. Soc. 14, iv.

Castle, E. J. (1956). Brit. I. Nutr. 10, 15.

Columbus, A. (1936). Forschungsdienst. 2, 208.

Lenkeit, W. (1930). Tierernähr. u. Tierz. 3, 631.

Lenkeit, W. (1932). Berl. Tierärztl. Wschr. 48, I7.

Lenkeit, W. \& Columbus, A. (1934). Arch wiss. prakt. Tierheilk. 68, 26.

Phillipson, A. T. (1939). Quart. F. exp. Physiol. 29, 395.

Sisson, S. (1953). Anatomy of the Domestic Animals, 4th ed. revised by J. D. Grossman. Philadelphia and London: W. B. Saunders Co. 